\title{
Views of Intern Doctors and Clinical Medical Teachers on the achievement of selected objectives of MBBS curriculum-2002 in Bangladesh
}

\author{
Brig Gen Dr M G Rasul', Major Gen. Prof. Dr. Debashish Saha², Professor Dr. Md. Humayun Kabir Talukder ${ }^{3}$
}

\begin{abstract}
Background: A competence based and community oriented with reflection of integrated and community based curriculum was introduced in 2002.

Objectives: To assess the achievement of objectives of MBBS curriculum-2002 by the Intern Doctors and Clinical Medical Teachers view in Bangladesh.

Materials and Methods: This descriptive cross sectional study surveyed on the performance of Intern Doctors about 60attributes of clinical and generic skills.

Results: The overall result revealed that the Interns' could achieve these skills just below the level of an expected standard. The low performance was observed in certain clinical, procedural and management skills like examination of eye, ear, per rectum examination, auscultation of heart and lung, lumber puncture, fluid aspiration, basic CPR, skin sensitivity test, ante natal check-up and conduction of normal labour, systematic interpretation of basic ECG etc. Though few Interns perceived to have attained mastery in some clinical skills but on the other hand $5-10 \%$ of other fellows did not even try the skill during the tenure.

Conclusion: All learning must occur in an appropriate clinical context and there should be a system of skill assessment for the Interns.
\end{abstract}

Key words: Curriculum, Clinical skill, Generic skill, Core Medical Training, Educational environment

\section{Introduction}

Under graduate medical education system of Bangladesh is pluralistic, with three key brands of doctors that define its production and supply to the National Health System i.e. from Government, private and NGOs led Medical Colleges. DGHS under MOH\&FW and BMDC had been the sole responsible bodies with the help of Medical Institutes to review and prepare a community-oriented and competencybased curriculum for undergraduate medical education in Bangladesh in 2002, with an aim to produce need-based doctors for the community to realize the National Goal ${ }^{5}$.

There was no formal curriculum for undergraduate Medical Education in Bangladesh except a syllabus published by BMDC before 1988. First scientifically developed

\section{Director, Shaheed Ziaur Rahman Medical College \& Hospital, Bogra \\ 2. Ex Major General, AFIP, Dhaka Cantonment \\ 3. Professor, Curriculum development and Evaluation, Center for Medical Education, Dhaka.}

Address of correspondence:

Brig Gen Dr. Md. Golam Rasul,

Director, Shaheed Ziaur Rahman Medical College \& Hospital,

Bogura

Email: amb21fd@gmail.com curriculum was introduced in the year 1988. Later on this mainly discipline based curriculum was reviewed and developed into a competence based and community oriented with reflection of integrated and community based curriculum in 2002. Finally, curriculum -2002 was reviewed and updated under need based and set up of national goal in the year 2012 and was introduced in the next year. Rapid grow of Medical Colleges at both public and private capacity, along with serious resource shortfall had been deteriorating the situation towards more complexity. There is gross deficiency of major infrastructure in most of the newly raised Medical Colleges along with deficiency of $63 \%$ Medical Teachers. Though curriculum is not the sole determinant of the outcome, yet, it is important as its objectives guide the faculty in preparing their instructions, tells the students where to go, what to do and what knowledge, skills and attitude they are to develop. However, the curricm has set out the ultimate objectives of MBBS course to produce competent, compassionate and dedicated health care professionaululs who will be able to perform the promised services dependably and accurately.

\section{Materials and Methods}

A descriptive cross sectional study was carried out through a written, English format, self-administered, semi-structured questionnaire for both Interns and Clinical Medical Teachers

Bangladesh Journal of Medical Education 2019;10(2):30-33. (C) 2019 Siddiquee et al., publisher and licensee Association for Medical Education. This is an Open Access article which permits unrestricted non-commercial use, provided the original work is properly cited. 
at nine different categories of Medical College Hospitals in Bangladesh. The questionnaire was consisted of 60 attributes of clinical, generic qualities with multiple Likert Scale options for response to determine competencies on the following variables under specific skill areas.

\section{Part-1: Clinical Skills}

Physical examination skills

Procedural kills

Medical management skills

Administrative tasks

\section{Part-2: Generic \& other skills}

Basic Generic skills

Moral \& legal codes of medical ethics

Health Education

National Health Interest

Continuing Medical Education (CME)

Team building \& leadership

The benchmark to meet the standard was set at rating scale $\geq 4$ inclinical and $\geq 5$ at generic skills. The response were taken from Intern Doctors $(n=401)$ currently undergoing Internship programme and Clinical Medical Teachers $(n=171)$ those who were appointed as clinical teacher, supervisor and immediate trainer for the Intern Doctors at various category of Medical College Hospitals in Bangladesh.

\section{Results}

Response rate was 92\% among Intern Doctors and $88 \%$ among Clinical Medical Teachers. The comprehensive results are shown in Tables 1 \& 2 under clinical and generic skills respectively:

Clinical skills Comprehensive views of

Table 1: respondents on Interns' achievement of specific objectives under clinical skills by mean of the mean of ratings

\begin{tabular}{lccccc}
\hline & \multicolumn{4}{c}{ Clinical skills } \\
\cline { 2 - 5 } Respondents & $\begin{array}{c}\text { Physical exam. skills } \\
(\overline{\mathrm{x}})\end{array}$ & $\begin{array}{c}\text { Procedural skills } \\
(\overline{\mathrm{x}})\end{array}$ & $\begin{array}{c}\text { Medical Management } \\
\text { skills }(\overline{\mathrm{x}})\end{array}$ & $\begin{array}{c}\text { Administrative tasks } \\
(\overline{\mathrm{x}})\end{array}$ & Mean of the mean \\
\hline Intern Doctors & 4.00 & 3.21 & 3.59 & 3.96 & 3.69 \\
Clinical Teachers & 3.52 & 3.18 & 3.39 & 3.52 & 3.40 \\
Mean of the mean & 3.76 & 3.19 & 3.49 & 3.74 \\
\hline
\end{tabular}

The mean of the mean of ratings by both the respondents in each skill area as shown in each Colum (Table-1) was just $>3$ (supervised) and the grand mean of the mean score of all skill areas was also 3.54 (supervised).

\section{Generic Skills}

Table 2: A comprehensive views of respondents on Interns' achievement of specific objectives on generic and other skills by mean of the mean of ratings

\begin{tabular}{lcccccccc}
\hline Respondent & $\begin{array}{c}\text { Basic } \\
\text { generic skills } \\
(\overline{\mathbf{x}})\end{array}$ & $\begin{array}{c}\text { Communicatio } \\
\mathbf{n} \text { skills }(\overline{\mathbf{x}})\end{array}$ & $\begin{array}{c}\text { Ethical \& } \\
\text { legal issues } \\
(\overline{\mathbf{x}})\end{array}$ & $\begin{array}{c}\text { National } \\
\text { Health } \\
\text { Interest }(\overline{\mathbf{x}})\end{array}$ & $\begin{array}{c}\text { Continuing } \\
\text { Medical } \\
\text { Education }(\overline{\mathbf{x}})\end{array}$ & $\begin{array}{c}\text { Health } \\
\text { Education } \\
(\overline{\mathbf{x}})\end{array}$ & $\begin{array}{c}\text { Team building } \\
\text { \& Leadership } \\
(\overline{\mathbf{x}})\end{array}$ & $\begin{array}{c}\text { Mean of } \\
\text { the mean }\end{array}$ \\
\hline Intern Doctors & 4.52 & 4.70 & 5.03 & 4.40 & 4.95 & 5.02 & 4.72 & 4.76 \\
Clinical Teachers & 3.58 & 3.91 & 4.17 & 3.74 & 4.22 & 4.32 & 4.09 \\
Mean of the & 4.05 & 4.30 & 4.60 & 4.07 & 4.58 & 4.67 & 4.40 \\
mean & & & & & & & 4.00 & \\
\hline
\end{tabular}

The mean of the mean score of ratings obtained from the respondents on eacharea of generic skills was just above 4 and the grand mean of the mean score of all skills area was 4.38 (somewhat adequate level). There were poor ratings on basic generic, communication skill and Health Education given by Clinical Teachers was $\geq 3$ (somewhat in-adequate).

\section{Barriers in achieving objectives}

The barriers were many as viewed by the respondents in their responses. All learning could not be established in an appropriate clinical context. Insufficient hospital equipment, lack of teaching and training aid, absence of qualified experienced teachers 
(89\%), unavailability of suitable patients for clinical practice, gender preference in hospital care, lack of co-operation between Clinical Teachers and Intern Doctors and above all absence of optimum educational environment were noteworthy for low achievement of objective by the Intern Doctors.

\section{Discussion}

The response rate among the Intern Doctors was $92 \%$ and Clinical Medical Teachers was $88 \%$. The study revealed that the objectives of MBBS curriculum-2002 were achieved by the Intern Doctors at a level just below the expected standard. The mean of the mean of performance score on all areas of clinical skills was 3.54 which resembles that the Interns can perform required skills "under supervision" only. Around 50\% Interns could score $>3$ (mean score) in acquiring competencies on certain clinical skills such as venipuncture, introduction of urinary catheter, insertion of nasogastric tube, including initial patient management and administrative tasks. On the other hand, $25-30 \%$ Interns scored low in certain other domains of clinical skills (mean score $<3$ ) such as physical examination of eye, ear and per rectal examination, auscultation of heart and lung, some procedural and practical skills like lumber puncture, fluid aspiration, skin sensitivity test, bedside pathological test, management skills like Ante Natal Checkup, conduction of normal labour, basic CPR, interpretation of ECG basics etc. About $38-45 \%$ Intern perceived that they can perform administrative tasks like admission, follow-up, discharge and transfer note without supervision except writing death note certificate.

The mean of the mean of adequacy of all areas of generic skills was 4.38 which resembles that the Interns were prepared in generic skills at "somewhat adequate" level. The preparedness on generic skills like communication skills ,compliance of work-time schedule, care for dying patient, coping with stress and emotion, balance between family and professional life, ethical issues, team building and leadership was low (mean score $>4$ ) than the expected standard. In Team building \& Leadership, more than 50\% Intern perceived that they were adequately prepared in understanding group dynamics, job of OHP to work within team environment and could appreciate constructive criticism. The mean score of ratings on adequacy of all the skill areas was $>4( \pm \mathrm{SD}=0.9000)$.

To achieve expected competencies in all areas of clinical and generic skills, there should be highly focused pre-clerkship period on basic and clinical science and all learning must take place in an appropriate clinical context with introduction of a system of Internship programme assessment.

\section{Notes on contributors}

MAJ GEN DEBASHISH SAHA, MBBS, FCPS, is a Commandant, Armed Forces Institute of Pathology, Dhaka Cantonment, Dhaka.

PROF H K TALUKDER, is a Professor, Curriculum Development and Evaluation, Centre for Medical Education(CME), Mohakhali, Dahaka.

\section{References}

1. Bandura A, (1993) Perceived self-efficacy in cognitive development and functioning. Educ Psychol., 28: 117-148. 10.1207/s15326985ep2802

2. Bradley J. Benson, (2014) Domain of Competence: Interpersonal and Communication, Clinical capabilities of graduates of an outcomes based integrated medical program.

3. Corbett EC Jr', Elnicki DM, Conaway MR, (2008) When should students learn essential physical examination skills? Views of internal medicine clerkship directors in North America, Acad Med. Jan;83(1):96-9.

4. BMDC, (2002) Curriculum for Under-Graduate Medical Education in Bangladesh-2002.

5. BMDC, (1973) Rotatory Internship Programme and logbook. GMC, (203) Good Medical Practice, UK

6. Helen A Scicluna ${ }^{1}$, Michael C Grim² ${ }^{2}$ Philip D Jones', Louis S Pilotto ${ }^{3}$ and H Patrick McNeil ${ }^{4}$, (2014) Improving the transition from medical school to internship- evaluation of preparation for internship course, 2014, BMC, Med Educ. 14: 23

7. Jan Hill ${ }^{1}$, Isobel E Rolfe ${ }^{2}$, Sallie-Anne Pearson ${ }^{2}, \&$ Andrew Heathcote ${ }^{1}$, (2013) Do junior doctors feel they are prepared for hospital practice?

8. Karen V Mann, John Ruedy, Noreen Millar \& Pantelis Andreou, (2005) Achievement of non-cognitive goals of undergraduate medical education: perceptions of medical students, residents, faculty and other health professionals. Med Educ;39;40-48

9. Y, Li N, Han Q, He S, Bae RS, et al. (2014) Performance of Physical Examination Skills in Medical Students during Diagnostic Medicine Course in a University Hospital of Northwest China. PLoS ONE 9(10): e109294. doi:10.1371/journal.pone. 0109294.

10. Mac Carrick G, Bradford S, Vial J, Carmichael A, (2007) Preparing our interns for hospital practice what makes for success in medical education? Foc Health Prof Educ. 9: 1-7.Google Scholar.

11. Marie C. Morris," Tom K. Gallagher, and Paul F. Ridgway, (2012) Tools used to assess medical students competence in procedural skills at the end of a primary medical degree: a systematic review, Med Educ Online, 17: 10.3402/meo.v17i0.18398.

12. McNeil HP, Scicluna H, Boyle P, Grimm MC, Gibson $K A$, Jones $P$, (2011) Successful development of generic 
12. McNeil HP, Scicluna H, Boyle P, Grimm MC, Gibson $K A$, Jones $P$, (2011) Successful development of generic capabilities in an undergraduate medical education program.

13. Murdoch-Eaton $D^{1}$, Whittle S. (2012) Generic skills in medical education: developing the tools for successful lifelong learning. Med Educ.2012 Jan;46(1):120-8.

14. Osman Slipicevic ${ }^{1}$, Izet Masic ${ }^{2}$, (2012) Management Knowledge and Skills Required in the Health Care System of the Federation Bosnia and Herzegovina, Mat Soc Med. Jun; 24(2): 106-111

15. Rolfe IE ${ }^{1}$, Pearson SA, Sanson-Fisher RW, Ringland C, Bayley S, Hart A, Kelly S. (2002) Which common clinical conditions should medical students be able to manage by graduation? A perspective from Australian interns.Med Teach. Jan; 24(1):16-22.
16. Rubin P, Franchi-Christopher D: New edition of Tomorrow's Doctors. Med Teach. (2002) 24: 368370.10.1080/0142159021000000816

17. Subha Ramani, Brandi N. Ring, Robert Lowe, David Hunter, (2010) A Pilot Study Assessing Knowledge of Clinical Signs and Physical Examination Skills in Incoming Medicine Residents, Journal of Graduate Medical Education.

18. Zanaton Haji Iksana, Effendi Zakariaa, Tamby Subahan Mohd Meeraha, Kamisah Osmana, Denise Koh Choon Liana, Siti Nur Diyana Mahmuda \& Pramela,Zonia SC, Stommel M, (2000) Interns' self-evaluations compared with their faculty's evaluations. Acad Med., 75: 74210.1097/00001888-200007000-00020. 